\title{
Effect of adenotonsillectomy on the growth, development, and comprehensive cognitive abilities of children with obstructive sleep apnea: a prospective single-arm study
}

\author{
Shan Shan ${ }^{1}$, Shuyu Wang ${ }^{2 *}$, Xue Yang ${ }^{3}$, Fan Liu ${ }^{2}$ and Linying Xiu ${ }^{2}$
}

\begin{abstract}
Background: Previous studies did not comprehensively examine the effect of adenotonsillectomy on growth and development, emotional state, quality of life, attention ability, and cognitive dysfunction in children with obstructive sleep apnea (OSA). This study aimed to explore the improvement effects of adenotonsillectomy on the growth, development, quality of life, and attention ability in children with OSA.

Methods: This prospective single-arm study involved children with OSA admitted at The No. 980 Hospital, Joint Logistics Support Force, PLA, China (02/2017-02/2018). The Myklebust Pupil Rating Scale (PRS), Inventory of Subjective Life Quality (ISLQ), Zung Self-rating Anxiety Scale (SAS), Conners Parent Symptom Questionnaire (PSQ), and Continuous Performance Task (CPT) were examined before and at 6 months after adenotonsillectomy.

Results: Forty-nine patients were enrolled. They all completed the 6-month follow-up. The body mass index increased after surgery (from $18.8 \pm 4.9$ to $19.3 \pm 4.3 \mathrm{~kg} / \mathrm{m}^{2}, P=0.008$ ). The total PRS score increased 6 months after surgery (from $73.8 \pm 12.7$ to $84.6 \pm 10.3, P<0.001$ ). All aspects of the ISLQ, except anxiety experience and physical emotion, were improved at 6 months after adenotonsillectomy (all $P<0.01$ ). The SAS score also decreased from $20.1 \pm 10.0$ to $12.8 \pm 6.6(P<0.001)$. All six dimensions of the PSQ, as assessed by the legal guardians, decreased after adenotonsillectomy (all $P<0.01$ ). The proportions of children with auditory and/or visual sustained attention abnormalities decreased after surgery.
\end{abstract}

Conclusions: After adenotonsillectomy, the PRS, ISLQ, and PSQ improved, and anxiety and auditory/visual sustained attention abnormalities decreased, suggesting positive impacts on the growth, development, quality of life, and comprehensive cognitive abilities of children with OSA.

Keywords: Obstructive sleep apnea, Children, Adenotonsillectomy, Growth, Development, Cognitive abilities

*Correspondence: hpyykyzy@163.com

${ }^{2}$ Department of Pediatrics, The No 980 Hospital, Joint Logistics Support

Force, PLA, Shijiazhuang, Hebei Province, China

Full list of author information is available at the end of the article

\section{Background}

Obstructive sleep apnea (OSA) is a breathing disorder characterized by recurrent complete or partial upper airway obstruction during sleep [1]. OSA interrupts the normal ventilation in sleep resulting in intermittent hypoxia and hypercapnia, frequent arousals, and sleep fragmentation. In addition, OSA may result in chronic snoring symptoms (commonly with sporadic pauses, snorts, or 
gasps), disturbed sleep patterns, and daytime neurobehavioral problems [1]. Apnea is defined as mouth and nose airflow decreased by $>90 \%$ for at least two breathing cycles, despite chest and abdomen movements during the event [2]. Hypopnea is defined as mouth and nose airflow decreased by $>30 \%$ compared with baseline, lasting for at least two breathing cycles, with event-related waking up or a decrease of $\geq 3 \%$ in oxygen saturation [2]. OSA is mild if $1 / \mathrm{h}<\mathrm{OAHI} \leq 5 / \mathrm{h}$, moderate if $5 / \mathrm{h}<\mathrm{OAHI} \leq 10 / \mathrm{h}$, or severe if OAHI $>10 / \mathrm{h}$ [1]. The prevalence of OSA is $1-6 \%$ in children $[1,3-6]$. Interventions for OSA in children include intranasal steroids [7, 8], montelukast [9], and continuous positive airway pressure (CPAP), but the only curative and definitive treatment is adenotonsillectomy $[10,11]$.

The complications of OSA in children include physiological and physical complications including impaired cardiac function (pulmonary arterial hypertension, heart dilation, chronic cardiac dysfunction, and increased in right heart afterload) [12, 13], impaired growth and development [14], and failure to thrive [15]. In addition to physical complications, OSA has detrimental effects on behavior and cognition [16, 17], development [14], emotional state $[18,19]$, quality of life $[18,20,21]$, attention ability [19, 22], and cognitive function [19, 23, 24].

Still, although adenotonsillectomy can cure OSA [10, $11]$ and improve diastolic function [25, 26], the previous studies on the impact of adenotonsillectomy on cognition and behavior yielded conflicting results. Indeed, Marcus et al. [11] reported that adenotonsillectomy improves the quality of life, impulsiveness, and emotional lability, but not attention and cognitive functions. A Cochrane review of only three studies suggested that evidence is lacking regarding the impact of adenotonsillectomy on quality of life, symptoms, and behavior [27, 28]. Of note, the available studies did not comprehensively examine the effect of adenotonsillectomy on growth and development, emotional state, quality of life, attention ability, and cognitive dysfunction. Furthermore, the previous studies were performed in Western settings, and very little data are available for Chinese children.

Therefore, this prospective study aimed to explore the improvement effects of adenotonsillectomy on the growth, development, quality of life, and attention ability in Chinese children with OSA.

\section{Methods}

\section{Study design and participants}

This prospective single-arm study involved children with OSA admitted to the Department of Otolaryngology at The No. 980 Hospital, Joint Logistics Support Force, PLA, China, from February 2017 to February 2018.
The diagnostic criteria for obstructive sleep apnea in children were based on the third edition of the International Classification of Sleep Disorders (ICSD-3) developed by the American Academy of Sleep Medicine (AASM) [29]. The inclusion criteria were 1) 6-12 years of age, 2) $>3$-month history of sleep snoring and mouth breathing, 3) consistent with the indications of adenotonsillar surgery (a. chronic tonsillitis occurs repeatedly and acutely, b. excessive tonsillitis hinders swallowing, breathing, and vocal function, c. chronic tonsillitis has become a "focus" causing lesions of other organs or is associated with lesions of adjacent organs, d. tonsillar hypertrophy leads to obstructive sleep apnea, e. drug treatment for adenoidal hypertrophy is ineffective, f. Severe adenoid hypertrophy, g complications such as otitis media, sinusitis, and posterior nostril drip, h. occlusive nasal sound, i. adenoid face, $j$. weight loss and developmental disorder), and 4) diagnosis of OSA was confirmed by PSG. The exclusion criteria were 1) central sleep apnea syndrome or hypopnea syndrome, 2) OSA complicated with other diseases (such as Down syndrome, severe craniofacial deformities, neuromuscular disorders, chronic lung diseases, sickle cell disease, metabolic diseases, or laryngomalacia), 3) refusal to undergo surgical intervention, or 4) surgical contraindications (including acute tonsillitis attack period, diseases of the hematopoietic system, hypocoagulation, or severe systemic diseases).

This study was approved by the Ethics Committee of The No. 980 Hospital, Joint Logistics Support Force, PLA, China (2021-KY-2). All patients' guardians provided written informed consent.

\section{Outcome measures}

Baseline data included age, sex, height, weight, body mass index (BMI), learning disabilities, quality of life, anxiety, behavioral problems, and attention ability.

Considering that all the methods used in this study were non-invasive and to avoid subjective bias as much as possible, we only informed the children and their parents of the cognitive and developmental results of this study and explained the reasons to the parents after the evaluation at 6 months postoperatively. In addition, the parents could withdraw at any time if they did no longer agree to participate in the study.

\section{Questionnaires and test methods}

The revised Myklebust Pupil rating scale (PRS) was used for screening for learning disabilities. The PRS evaluates auditory comprehension, spoken language, orientation, motor coordination, and personal-social behavior. It is summarized as verbal subtotal, nonverbal subtotal, and total scores. The Chinese version of the PRS has coefficients of reliability $>0.95$ for both subscores [30]. 
The Inventory of subjective life quality (ISLQ) includes 52 items that assess family life, peer relationship, school life, living environment, self-knowledge, the cognitive component, the experience of depression, the experience of anxiety, physical emotion, and emotional component [31]. It has been validated in Chinese, and Cronbach's $\alpha$ is 0.89 [32].

The Zung Self-Rating Anxiety Scale (SAS)-CR is a widely used tool for screening anxiety based on manifestations in the cognitive, autonomic, motor, and central nervous system dimensions [33]. It has been validated in Chinese, with a Cronbach's $\alpha$ of 0.931 [34].

Conners parent symptom questionnaire (PSQ) evaluates behavioral markers that include hyperactivity, compulsive actions, perfectionism, playing up in class, violence, aggressiveness, mathematics difficulties, language difficulties, fear of separation, social issues, and emotional anguish [35]. It is validated in Chinese and has a Cronbach's $\alpha>0.85$ [36].

Attention ability (visual and/or auditory) was assessed by the Continuous Performance Task (CPT), which included sustained attention abnormalities of visual sense, auditory, and both visual and auditory [37].

Overnight PSG monitoring was performed using Condi E polysomnography equipment. Electroencephalogram, electrooculogram, chin electromyography, electromyography of the lower limbs (leg movement sensor), respiratory airflow (oral-nasal temperature airflow sensor, nasal pressure sensor), respiratory effort (chest and abdominal band), blood oxygen saturation (pulse oxygen meter), body position, snoring, electrocardiograph, and real-time digital video were recorded synchronically.

\section{Surgical intervention and follow-up}

Adenotonsillectomy was performed by one of three senior deputy doctors with over 10 years of relevant surgical experience. The above questionnaires and tests were evaluated in the inpatient department before surgery and in the outpatient department 6 months after surgery.

\section{Statistical analysis}

All data were analyzed using SPSS 22.0 (IBM, Armonk, NY, USA). The Kolmogorov-Smirnov normality test was performed on all continuous variables. Normally distributed continuous variables were presented as means \pm standard deviations and analyzed using paired $t$-test. Non-normally distributed continuous variables were presented as medians (interquartile ranges) and analyzed using Wilcoxon's test. The categorical data were presented as $\mathrm{n}(\%)$ and analyzed using the McNemanr test for non-ranked data and Wilcoxon's test for ranked data. All statistical tests were two-tailed, and $P$-values $<0.05$ were considered statistically significant.

\section{Results}

Characteristics of the participants

During the study period, 67 children were assessed for eligibility, but seven were excluded (refused surgery, $n=5$; surgical contraindication, $n=2$ ). Sixty children were enrolled, but 11 were excluded (change in surgery, $n=3$; loss to follow-up, $n=5$; refused to continue participation after being informed of the cognitive results, $n=3)$. Therefore, 49 patients were included in the analysis since they completed the 6-month follow-up and assessments (Fig. 1). Their characteristics are shown in

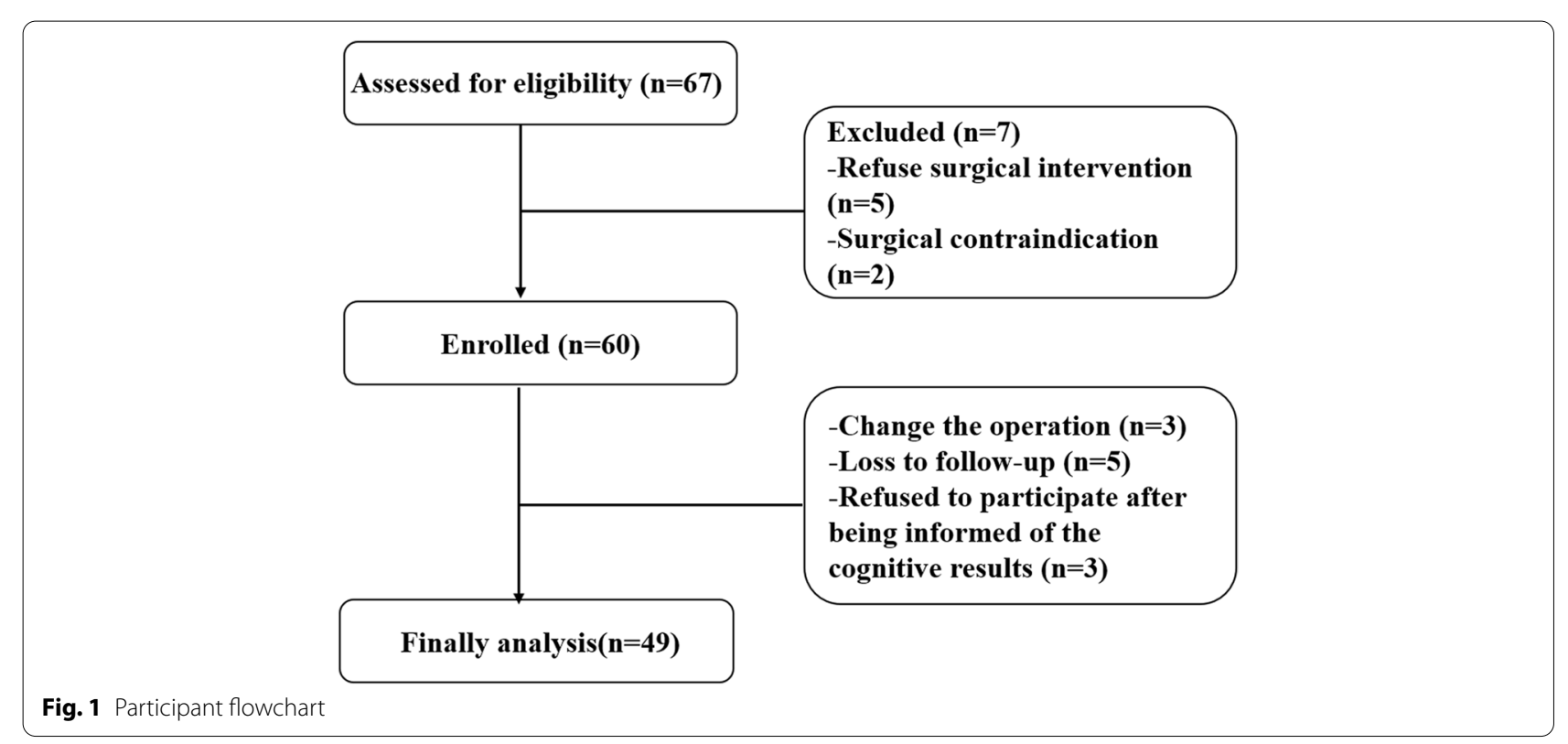


Table 1 Characteristics and growth and development of the patients

\begin{tabular}{llll}
\hline Parameters & Prior to surgery $(\boldsymbol{n}=\mathbf{4 9})$ & At $\mathbf{6}$ months after surgery $(\boldsymbol{n}=\mathbf{4 9 )}$ & $\boldsymbol{P}$ \\
\hline Age (years) & $8.5 \pm 1.9$ & $9.2 \pm 1.8$ & $<.001$ \\
Weight $(\mathrm{kg})$ & $35.4 \pm 14.6$ & $39.1 \pm 14.7$ & $<.001$ \\
Height $(\mathrm{cm})$ & $135.1 \pm 12.5$ & $140.1 \pm 12.9$ & $<0.001$ \\
Body mass index $\left(\mathrm{kg} / \mathrm{m}^{2}\right)$ & $18.8 \pm 4.9$ & $19.3 \pm 4.3$ & 0.008 \\
Z score & $-0.35(-0.79,0.67)$ & $-0.34(-0.74,0.64)$ & 0.964 \\
Obstructive apnea/hypopnea index & $2.60(1.60,7.20)$ & $0.80(0.50,2.15)$ & $<0.001$ \\
Learning disabilities-Pupil Rating Scale & & $84.6 \pm 10.3$ & $<0.001$ \\
$\quad$ Total & $73.8 \pm 12.7$ & $37.1 \pm 10.8$ & $<0.001$ \\
$\quad$ Verbal & $28.0 \pm 10.7$ & $47.4 \pm 3.6$ & 0.047 \\
$\quad$ Non-verbal & $45.7 \pm 3.9$ & & \\
\hline
\end{tabular}

Table 2 Changes in quality of life before and after surgery

\begin{tabular}{|c|c|c|c|c|}
\hline & & $\begin{array}{l}\text { Prior to } \\
\text { surgery } \\
(n=49)\end{array}$ & $\begin{array}{l}\text { At } 6 \text { months } \\
\text { after surgery } \\
(n=49)\end{array}$ & $P$ \\
\hline \multirow[t]{11}{*}{ ISLQ } & Family life & $5.1 \pm 1.5$ & $5.8 \pm 1.2$ & 0.001 \\
\hline & Peer interaction & $5.2 \pm 1.2$ & $5.8 \pm 1.3$ & 0.003 \\
\hline & School life & $3.8 \pm 1.9$ & $4.7 \pm 1.6$ & $<0.001$ \\
\hline & Living environment, & $4.6 \pm 1.6$ & $5.3 \pm 1.5$ & $<0.001$ \\
\hline & Self-awareness & $4.6 \pm 1.7$ & $5.7 \pm 1.8$ & $<0.001$ \\
\hline & Cognitive component & $43.2 \pm 16.5$ & $53.6 \pm 14.1$ & $<0.001$ \\
\hline & Depression experience & $4.0 \pm 2.6$ & $5.2 \pm 2.1$ & $<0.001$ \\
\hline & Anxiety experience & $5.4 \pm 1.9$ & $5.7 \pm 1.9$ & 0.185 \\
\hline & Physical emotion & $5.0 \pm 1.8$ & $5.5 \pm 1.7$ & 0.078 \\
\hline & Emotional component & $48.7 \pm 19.9$ & $55.1 \pm 19.2$ & 0.001 \\
\hline & Total & $41.2 \pm 15.7$ & $53.3 \pm 13.4$ & $<0.001$ \\
\hline SAS & & $20.1 \pm 10.0$ & $12.8 \pm 6.6$ & $<0.001$ \\
\hline
\end{tabular}

SAS Zung Self-rating anxiety scale, ISLQ Inventory of subjective life quality

Table 1 . The children were $8.5 \pm 1.9$ years old before surgical intervention. Their body mass index increased after surgery (from $18.8 \pm 4.9$ to $19.3 \pm 4.3 \mathrm{~kg} / \mathrm{m}^{2}, P=0.008$ ). The OAHI reduced after surgery [from $2.60(1.60,7.20)$ to $0.80(0.50,2.15), P<0.001]$.

\section{Myklebust PRS}

The total PRS score increased at 6 months after surgery (from $73.8 \pm 12.7$ to $84.6 \pm 10.3, P<0.001$ ), including the verbal (from $28.0 \pm 10.7$ to $37.1 \pm 10.8, P<0.001$ ) and non-verbal (from $45.7 \pm 3.9$ to $47.4 \pm 3.6, P=0.047$ ) subscores (Table 1).

\section{Quality of life and anxiety}

Table 2 shows that the total score and all aspects of the ISLQ, except anxiety experience (from $5.4 \pm 1.9$ to $5.7 \pm 1.9, P=0.185$ ) and physical emotion (from $5.0 \pm 1.8$
Table 3 Changes in Conners PSQ before and after surgery

\begin{tabular}{|c|c|c|c|}
\hline Conners PSQ & Prior to surgery & $\begin{array}{l}\text { At } 6 \text { months } \\
\text { after surgery }\end{array}$ & $P$ \\
\hline Conduct & $61.5 \pm 15.4$ & $50.8 \pm 10.1$ & $<0.001$ \\
\hline $\begin{array}{l}\text { Proportion of abnormality, } \\
\mathrm{n}(\%)\end{array}$ & $9(18.4 \%)$ & $2(4.1 \%)$ & 0.039 \\
\hline Learning & $61.3 \pm 12.7$ & $49.2 \pm 10.7$ & $<0.001$ \\
\hline $\begin{array}{l}\text { Proportion of abnormality, } \\
\text { n (\%) }\end{array}$ & $22(44.9 \%)$ & $6(2.2 \%)$ & $<0.001$ \\
\hline Somatopsychic disturbance & $60.8 \pm 18.3$ & $49.8 \pm 11.0$ & $<0.001$ \\
\hline $\begin{array}{l}\text { Proportion of abnormality, } \\
\text { n (\%) }\end{array}$ & $11(22.4 \%)$ & $3(6.1 \%)$ & 0.008 \\
\hline Impulsivity and hyperactivity & $58.9 \pm 11.1$ & $46.5 \pm 9.1$ & $<0.001$ \\
\hline $\begin{array}{l}\text { Proportion of abnormality, } \\
\text { n (\%) }\end{array}$ & $30(61.2 \%)$ & $13(26.5 \%)$ & $<0.001$ \\
\hline Anxiety & $55.0 \pm 9.9$ & $49.9 \pm 7.6$ & 0.002 \\
\hline $\begin{array}{l}\text { Proportion of abnormality, } \\
\mathrm{n}(\%)\end{array}$ & $17(34.7 \%)$ & $4(8.2 \%)$ & 0.001 \\
\hline Hyperactivity index & $60.3 \pm 11.4$ & $49.0 \pm 8.9$ & $<0.001$ \\
\hline $\begin{array}{l}\text { Proportion of abnormality, } \\
\mathrm{n}(\%)\end{array}$ & $32(65.3 \%)$ & $14(28.6 \%)$ & $<0.001$ \\
\hline
\end{tabular}

PSQ Parent symptom questionnaire

to $5.5 \pm 1.7, P=0.078$ ), were improved at 6 months after adenotonsillectomy (all $P<0.01$ ). The SAS score also decreased significantly from $20.1 \pm 10.0$ to $12.8 \pm 6.6$ $(P<0.001)$.

\section{Conners PSQ}

The results of Conners PSQ are shown in Table 3. All six dimensions of the PSQ, including conduct $(61.5 \pm 15.4$ vs. $50.8 \pm 10.1)$, learning $(61.3 \pm 12.7$ vs. $49.2 \pm 10.7)$, somatopsychic disturbance $(60.8 \pm 18.3$ vs. $49.8 \pm 11.0)$, impulsivity and hyperactivity $(58.9 \pm 11.1$ vs. $46.5 \pm 9.1)$, anxiety $(55.0 \pm 9.9$ vs. $49.9 \pm 7.6)$, and hyperactivity index $(60.3 \pm 11.4$ vs. $49.0 \pm 8.9)$, as assessed by the legal guardians, significantly decreased 
after adenotonsillectomy (all $P<0.01$ ). Furthermore, the proportions of abnormality also showed a significant decrease in all six dimensions, which was in line with the assessment of absolute value (all $P<0.05$ ).

\section{Attention ability}

As displayed in Table 4, 21 children (42.9\%) had various visual sense sustained attention abnormalities before surgery, while none had such abnormality at 6 months after surgery. The percentage of children who had severe, moderate, mild, and suspect visual sense sustained attention abnormality significantly decreased after surgical intervention (from $26(53.1 \%)$ to $3(6.1 \%)$, $P<0.001$ ).

Various degrees of auditory sustained attention abnormality were found in 41 (83.7\%) children before surgery and $21(42.9 \%)$ after surgery $(P<0.001)$. As for severe auditory sustained attention abnormality, there were $36(73.5 \%)$ patients before surgery, while there were merely $12(24.5 \%)$ after surgery.

Before surgery, 29 (59.2\%) children had both visual and auditory sustained attention abnormalities, and this number decreased to nine (18.4\%) after surgery $(P<0.001)$. All 19 patients with severe visual and auditory sustained attention abnormalities showed improvement of various degrees after surgical intervention.

Table 4 Changes in attention ability before and after surgery

\begin{tabular}{llll}
\hline $\begin{array}{l}\text { Sustained attention } \\
\text { abnormality }\end{array}$ & Prior to surgery & $\begin{array}{l}\text { At } 6 \text { months } \\
\text { after surgery }\end{array}$ & $P$ \\
\hline $\begin{array}{l}\text { Visual, n (\%) } \\
\text { Severe }\end{array}$ & $16(32.7 \%)$ & 0 & $<0.001$ \\
Moderate & $3(6.1 \%)$ & 0 & \\
Mild & $2(4.1 \%)$ & 0 & \\
Suspect & $5(10.2 \%)$ & $3(6.1 \%)$ & \\
No & $23(46.9 \%)$ & $46(93.9 \%)$ & \\
Auditory, n (\%) & & & $<0.001$ \\
Severe & $36(73.5 \%)$ & $12(24.5 \%)$ & \\
Moderate & $2(4.1 \%)$ & 0 & \\
Mild & $3(6.1 \%)$ & $9(18.4 \%)$ & \\
Suspect & 0 & 0 & \\
No & $8(16.3 \%)$ & $28(57.1 \%)$ & \\
Both auditory and visual, & & & \\
n (\%) & & 0.001 \\
$\quad$ Severe & $19(38.8 \%)$ & 0 & \\
Moderate & $5(10.2 \%)$ & $1(2.0 \%)$ & \\
Mild & $5(10.1 \%)$ & $8(16.3 \%)$ & \\
Suspect & $3(6.1 \%)$ & $5(10.2 \%)$ & \\
No & $17(34.7 \%)$ & $35(71.4 \%)$ & \\
\hline
\end{tabular}

\section{Discussion}

Previous studies showed that children with OSA display several issues in physical health [12], development [14], and comprehensive cognitive functions [15-17, 19, 22-24]. Shpirer et al. [38] showed that hypoxemia correlated with attentional dysfunction in children with OSA. Adenotonsillectomy is the only definitive treatment for OSA [10, 11]. Still, previous studies did not comprehensively examine the effect of adenotonsillectomy on growth and development, emotional state, quality of life, attention ability, and cognitive dysfunction in children with OSA [27, 28]. Since adenotonsillectomy removes the excess tissues that cause upper airway obstruction, adenotonsillectomy could improve oxygenation during sleep, improve sleep quality, and perhaps mitigate cognitive dysfunction. This study suggests that timely adenotonsillectomy could improve the PRS, ISLQ, and PSQ and decrease anxiety and auditory/visual sustained attention abnormalities, suggesting positive impacts on the growth, development, quality of life, and comprehensive cognitive abilities of children with OSA. A study showed that the accuracy of assessing OSA impacts was higher when using multiple tools [39]. Conners PSQ is the most commonly used tool for children's behavioral assessment, both at home and school [40]. Conner's PSQ can be used clinically or in research. Ali et al. [41] showed that children with high-risk breathing disorders had higher scores on Conner's PSQ.

There is no comprehensive study on the effect of adenotonsillectomy on children's development, but some studies provide a few clues. A meta-analysis of three studies revealed moderate-quality evidence for improvements in quality of life, OSA symptoms, and behavior after adenotonsillectomy and high-quality evidence for lack of effect on neurocognitive performance [27]. Marcus et al. [11] reported that adenotonsillectomy improved the quality of life, impulsiveness, and emotional lability, with significant improvements in comprehensive cognitive abilities. Friedman et al. [42] showed that OSA-related cognitive dysfunction is reversible by adenotonsillectomy. Similarly, a pilot study by Goldstein et al. [43] showed that the scores of a standardized measure of behavior improved after adenotonsillectomy for upper airway obstruction. An early study by Gozal [44] showed that adenotonsillectomy improved the mean grades of children with sleep breathing disorders.

Regarding development, Nachalon et al. [14] reported improvements in growth, systemic inflammation, and calorie intake after adenotonsillectomy in children with OSA. Adenotonsillectomy could decrease the proportion of OSA children $<25$ th percentile for weight, height, and BMI [45]. 
Furthermore, a previous study focused on comparing the quality of life and anxiety between the children with OSA and healthy children. It revealed the lower quality of life and higher anxiety in children with OSA [46], supported by a study showing higher anxiety and depression with sleep disturbances also in adults [47].

In the present study, adenotonsillectomy improved children's growth with OSA and improved their quality of life and comprehensive cognitive abilities. This is supported by Wei et al. [48], who showed improvements in sleep quality and behavior after adenotonsillectomy. Of course, various scales and tools are available to assess the changes in growth and development, quality of life, behavior, and attention ability. The discrepancies among studies could be due, at least in part, to such differences. Nevertheless, large-scale multicenter trials should be performed to determine the effects of adenotonsillectomy in children with OSA in multiple aspects.

This study has limitations. This was a single-arm study, and the lack of a comparator group precludes a firm conclusion on the effect of adenotonsillectomy on the development of children. Besides, the sample size was small and from a single center. Future studies should address these issues and examine biochemical parameters like low-grade inflammation, immune system, and stress hormones.

\section{Conclusion}

In conclusion, after adenotonsillectomy, the PRS, ISLQ, and PSQ improved, and anxiety and auditory/visual sustained attention abnormalities decreased, suggesting positive impacts on the growth, development, quality of life, and comprehensive cognitive abilities of children with OSA. The results could help improve the management of children with OSA.

\begin{abstract}
Abbreviations
AASM: American Academy of Sleep Medicine; BMI: Body mass index; CPAP: Continuous positive airway pressure; CPT: Continuous Performance Task; ICSD3: The third edition of the International Classification of Sleep Disorders; ISLQ: Inventory of subjective life quality; OAHI: Obstructive apnea/hypopnea index; OSA: Obstructive sleep apnea; PRS: Pupil rating scale; PSQ: Parent symptom questionnaire; SAS: Self-rating anxiety scale.
\end{abstract}

\section{Acknowledgments}

Not applicable.

\section{Authors' contributions}

SS coordinated the study, designed and performed the experiments, and wrote the paper. SYW conceived the study and analyzed the experiments. $X Y$ analyzed the data and revised the paper. FL and LYX carried out the data collection. All authors reviewed the results and approved the final version of the manuscript.

\section{Funding}

This study was funded by the 2018 Key Project of Medical Science Research of Provincial Health Commission of Hebei (20180908). The funders had no role in study design, data collection, and analysis, decision to publish, or manuscript preparation.

\section{Availability of data and materials}

All data generated or analyzed during this study are included in this published article.

\section{Declarations}

\section{Ethics approval and consent to participate}

This study was approved by the Ethics Committee of The No. 980 Hospital, Joint Logistics Support Force, PLA, China (2021-KY-2). All procedures performed in studies involving human participants were in accordance with the ethical standards of the institutional and/or national research committee and with the 1964 Helsinki declaration and its later amendments or comparable ethical standards. All patients' guardians provided written informed consent.

\section{Consent for publication}

Not applicable.

\section{Competing interests}

All authors declare that they have no competing interests.

\section{Author details}

'Department of Otolaryngology Head and Neck Surgery, The No 980 Hospital, Joint Logistics Support Force, PLA, Shijiazhuang, Hebei Province, China. ${ }^{2}$ Department of Pediatrics, The No 980 Hospital, Joint Logistics Support Force, PLA, Shijiazhuang, Hebei Province, China. ${ }^{3}$ Department of Otolaryngology Head and Neck Surgery, Handan Central Hospital, Handan, Hebei Province, China.

Received: 30 March 2021 Accepted: 5 January 2022

Published online: 15 January 2022

\section{References}

1. Marcus $C L$, Brooks LJ, Draper KA, Gozal D, Halbower AC, Jones J, et al. Diagnosis and management of childhood obstructive sleep apnea syndrome. Pediatrics. 2012;130(3):576-84.

2. Chinese working group on the diagnosis and treatment of OSA in children, Pediatric Division of Otolaryngology Head and Neck Surgery Branch, Chinese Medical Association, Respiratory Group, Pediatrics Society of Chinese Medical Association, et al. Chinese guidelines for diagnosis and treatment of obstructive sleep apnea in children. Chin J Orthorhinol Head Neck Surg. 2020;55(08):729-47.

3. Brunetti L, Rana S, Lospalluti ML, Pietrafesa A, Francavilla R, Fanelli M, et al. Prevalence of obstructive sleep apnea syndrome in a cohort of 1,207 children of southern Italy. Chest. 2001;120(6):1930-5.

4. Sogut A, Altin R, Uzun L, Ugur MB, Tomac N, Acun C, et al. Prevalence of obstructive sleep apnea syndrome and associated symptoms in 3--11-year-old Turkish children. Pediatr Pulmonol. 2005;39(3):251-6.

5. Bixler EO, Vgontzas AN, Lin HM, Liao D, Calhoun S, Vela-Bueno A, et al. Sleep disordered breathing in children in a general population sample: prevalence and risk factors. Sleep. 2009;32(6):731-6.

6. Li AM, So HK, Au CT, Ho C, Lau J, Ng SK, et al. Epidemiology of obstructive sleep apnoea syndrome in Chinese children: a two-phase community study. Thorax. 2010;65(11):991-7.

7. Kuhle S, Urschitz MS. Anti-inflammatory medications for obstructive sleep apnea in children. Cochrane Database Syst Rev. 2011:1:CD007074.

8. Zhang L, Mendoza-Sassi RA, Cesar JA, Chadha NK. Intranasal corticosteroids for nasal airway obstruction in children with moderate to severe adenoidal hypertrophy. Cochrane Database Syst Rev. 2008;3:CD006286.

9. Goldbart AD, Greenberg-Dotan S, Tal A. Montelukast for children with obstructive sleep apnea: a double-blind, placebo-controlled study. Pediatrics. 2012;130(3):e575-80.

10. Roland PS, Rosenfeld RM, Brooks LJ, Friedman NR, Jones J, Kim TW, et al. Clinical practice guideline: Polysomnography for sleep-disordered 
breathing prior to tonsillectomy in children. Otolaryngol Head Neck Surg. 2011;145(1 Suppl):S1-15.

11. Marcus CL, Moore RH, Rosen CL, Giordani B, Garetz SL, Taylor HG, et al. A randomized trial of adenotonsillectomy for childhood sleep apnea. N Engl J Med. 2013;368(25):2366-76.

12. Blechner M, Williamson AA. Consequences of obstructive sleep apnea in children. Curr Probl Pediatr Adolesc Health Care. 2016;46(1):19-26.

13. Manti S, Parisi GF, Giacchi V, Sciacca P, Tardino L, Cuppari C, et al. Pilot study shows right ventricular diastolic function impairment in young children with obstructive respiratory disease. Acta Paediatr. 2019;108(4):740-4.

14. Nachalon Y, Lowenthal N, Greenberg-Dotan S, Goldbart AD. Inflammation and growth in young children with obstructive sleep apnea syndrome before and after adenotonsillectomy. Mediat Inflamm. 2014;2014:146893.

15. Marcus CL, Carroll JL, Bamford O, Pyzik P, Loughlin GM. Supplemental oxygen during sleep in children with sleep-disordered breathing. Am J Respir Crit Care Med. 1995;152(4 Pt 1):1297-301.

16. Galland B, Spruyt K, Dawes P, McDowall PS, Elder D, Schaughency E. Sleep disordered breathing and academic performance: a Meta-analysis. Pediatrics. 2015;136(4):e934-46.

17. Gottlieb DJ, Chase C, Vezina RM, Heeren TC, Corwin MJ, Auerbach SH, et al. Sleep-disordered breathing symptoms are associated with poorer cognitive function in 5-year-old children. J Pediatr. 2004;145(4):458-64.

18. Tran KD, Nguyen CD, Weedon J, Goldstein NA. Child behavior and quality of life in pediatric obstructive sleep apnea. Arch Otolaryngol Head Neck Surg. 2005;131(1):52-7.

19. Giordani B, Hodges EK, Guire KE, Ruzicka DL, Dillon JE, Weatherly RA, et al. Neuropsychological and behavioral functioning in children with and without obstructive sleep apnea referred for tonsillectomy. J Int Neuropsychol Soc. 2008;14(4):571-81.

20. Franco RA Jr, Rosenfeld RM, Rao M. First place--resident clinical science award 1999. Quality of life for children with obstructive sleep apnea. Otolaryngol Head Neck Surg. 2000;123(1 Pt 1):9-16.

21. Jackman AR, Biggs SN, Walter LM, Embuldeniya US, Davey MJ, Nixon GM, et al. Sleep disordered breathing in early childhood: quality of life for children and families. Sleep. 2013;36(11):1639-46.

22. Wu J, Gu M, Chen S, Chen W, Ni K, Xu H, et al. Factors related to pediatric obstructive sleep apnea-hypopnea syndrome in children with attention deficit hyperactivity disorder in different age groups. Medicine (Baltimore). 2017;96(42):e8281.

23. Taylor HG, Bowen SR, Beebe DW, Hodges E, Amin R, Arens R, et al. Cognitive effects of adenotonsillectomy for obstructive sleep apnea. Pediatrics. 2016;138(2).

24. Otero L, del Carmen FM, Riveros-Rivera A, Hidalgo P. Cognitive impairment and obstructive sleep apnea. In: updates in sleep neurology and obstructive sleep apnea. Edn. London: IntechOpen; 2018.

25. Domany KA, Huang G, Hossain MM, Schuler CL, Somers VK, Daniels SR, et al. Effect of Adenotonsillectomy on cardiac function in children age 5-13 years with obstructive sleep apnea. Am J Cardiol. 2021;141:120-6.

26. Ugur MB, Dogan SM, Sogut A, Uzun L, Cinar F, Altin R, et al. Effect of adenoidectomy and/or tonsillectomy on cardiac functions in children with obstructive sleep apnea. ORL J Otorhinolaryngol Relat Spec. 2008:70(3):202-8

27. Venekamp RP, Hearne BJ, Chandrasekharan D, Blackshaw H, Lim J, Schilder AG. Tonsillectomy or adenotonsillectomy versus non-surgical management for obstructive sleep-disordered breathing in children. Cochrane Database Syst Rev. 2015;10:CD011165.

28. Burton MJ, Goldstein NA, Rosenfeld RM. Cochrane corner: extracts from the cochrane library: tonsillectomy or adenotonsillectomy versus non-surgical management for obstructive sleep-disordered breathing in children. Otolaryngol Head Neck Surg. 2016;154(4):581-5.

29. Sateia MJ. International classification of sleep disorders-third edition: highlights and modifications. Chest. 2014;146(5):1387-94.

30. Zhong W, Jin J, SuYing A, Ni Y, Ke-qing H, XueQiong L, et al. Reliability and validity of revised pupil rating scale in regional implementation of learning disability screening. Chinese Prev Med. 2010;11:682-5.

31. Freeman RD, Fast DK, Burd L, Kerbeshian J, Robertson MM, Sandor P. An international perspective on Tourette syndrome: selected findings from 3,500 individuals in 22 countries. Dev Med Child Neurol. 2000;42(7):436-47.
32. Cheng ZH, Gao BL. The inventory of subjective life quality for child and adolescent: development, reliability, and validity (in Chinese). Chin J Clin Psychol. 1998;6(1):11-6.

33. Zung WW. A rating instrument for anxiety disorders. Psychosomatics. 1971;12(6):371-9.

34. Pang Z, Tu D, Cai Y. Psychometric properties of the SAS, BAl, and S-Al in Chinese University Students. Front Psychol. 2019;10:93.

35. Conners CK, Pitkanen J, Rzepa SR. Conners comprehensive behavior rating scale. In: Kreutzer JS, DeLuca J, Caplan B, editors. Encyclopedia of clinical neuropsychology. Berlin: Springer; 2011.

36. Gau SS, Soong WT, Chiu YN, Tsai WC. Psychometric properties of the Chinese version of the Conners' parent and teacher rating scales-revised: short form. J Atten Disord. 2006;9(4):648-59.

37. Luo XR, Li XR. A study on continuous performance task in children with attention deficit hyperactivity disorder. Chin J Clin Psychol. 2002;2002(02):85-7.

38. Shpirer I, Elizur A, Shorer R, Peretz RB, Rabey JM, Khaigrekht M. Hypoxemia correlates with attentional dysfunction in patients with obstructive sleep apnea. Sleep Breath. 2012;16(3):821-7.

39. Chervin RD, Ruzicka DL, Archbold KH, Dillon JE. Snoring predicts hyperactivity four years later. Sleep. 2005;28(7):885-90.

40. DuY, Kou J, Coghill D. The validity, reliability and normative scores of the parent, teacher and self report versions of the strengths and difficulties questionnaire in China. Child Adolesc Psychiatry Ment Health. 2008;2(1):8.

41. Ali NJ, Pitson DJ, Stradling JR. Snoring, sleep disturbance, and behaviour in 4-5 year olds. Arch Dis Child. 1993;68(3):360-6.

42. Friedman BC, Hendeles-Amitai A, Kozminsky E, Leiberman A, Friger $\mathrm{M}$, Tarasiuk $\mathrm{A}$, et al. Adenotonsillectomy improves neurocognitive function in children with obstructive sleep apnea syndrome. Sleep. 2003;26(8):999-1005.

43. Goldstein NA, Post JC, Rosenfeld RM, Campbell TF. Impact of tonsillectomy and adenoidectomy on child behavior. Arch Otolaryngol Head Neck Surg. 2000;126(4):494-8.

44. Gozal D. Sleep-disordered breathing and school performance in children. Pediatrics. 1998;102(3 Pt 1):616-20.

45. Hyun SM, Kim DY, Yi JS, Lee BJ, Chung YS. The effect of Adenotonsillectomy on growth in Prepubertal children. Sleep Med Res. 2016;7(1):21-5

46. Shan S, Wang S, Miao Y. The study of life quality in children with obstructive sleep apnea. J Clin Ororhinol Head Neck Surg. 2018;032(015):1182-4.

47. Barzegar M, Sadeghi Bahmani D, Nehzat N, Kiani M, Hashemi N, Mirmosayyeb $\mathrm{O}$, et al. Comparison of sleep complaints and quality of life between patients with neuromyelitis optica spectrum disorder (NMOSD) and healthy controls. Mult Scler Relat Disord. 2019;32:81-7.

48. Wei JL, Mayo MS, Smith HJ, Reese M, Weatherly RA. Improved behavior and sleep after adenotonsillectomy in children with sleep-disordered breathing. Arch Otolaryngol Head Neck Surg. 2007;133(10):974-9.

\section{Publisher's Note}

Springer Nature remains neutral with regard to jurisdictional claims in published maps and institutional affiliations.

\footnotetext{
Ready to submit your research? Choose BMC and benefit from:

- fast, convenient online submission

- thorough peer review by experienced researchers in your field

- rapid publication on acceptance

- support for research data, including large and complex data types

- gold Open Access which fosters wider collaboration and increased citations

- maximum visibility for your research: over $100 \mathrm{M}$ website views per year
}

At BMC, research is always in progress.

Learn more biomedcentral.com/submissions 